\title{
LOCAL CLIMATE CLASSIFICATION AND URBAN HEAT/DRY ISLAND IN MATSUYAMA PLAIN
}

\author{
Deepak Bikram THAPA CHHETRI ${ }^{1}$, Yoshifumi FUJIMORI ${ }^{2}$ and Ryo MORIWAKI ${ }^{3}$ \\ ${ }^{1}$ Graduate student, Graduate school of Science and Engineering, Ehime University \\ (Bunkyocho 3, Matsuyama, Ehime 790-8577, Japan) \\ E-mail:deepak.thapa.12@cee.ehime-u.ac.jp \\ ${ }^{2}$ Member of JSCE, Assistant Professor, Graduate school of Science and Engineering, Ehime University \\ (Bunkyocho 3, Matsuyama, Ehime 790-8577, Japan) \\ E-mail:fujimori@cee.ehime-u.ac.jp \\ ${ }^{3}$ Member of JSCE, Professor, Graduate school of Science and Engineering, Ehime University \\ (Bunkyocho 3, Matsuyama, Ehime 790-8577, Japan) \\ E-mail:moriwaki@cee.ehime-u.ac.jp
}

\begin{abstract}
This paper analyses and standardize the urban heat island (UHI) and urban dry island (UDI) effects in Matsuyama plane, focusing on the Local climate Zones (LCZs). LCZs classifies the landscape into homogeneous types based on structural type, land surface cover, materials used and human activities. This standard classification has made urban studies more meaningful and easy to compare the results with various cities globally. The LCZ map for Matsuyama was created using Landsat images, Google Earth and SAGA-GIS software. Four out of twenty-five in-situ meteorological stations network available in Matsuyama plane for different atmospheric studies were selected to represent the unique LCZ area each.UHI favourable days (August 1-6) were selected using Japanese Meteorological Agency (JMA) data. The results show $\mathrm{LCZ}$ with the compact mid rise building were on average $0.6^{\circ} \mathrm{C}$ cooler at day time and $2^{\circ} \mathrm{C}$ warmer at night time than $\mathrm{LCZ}$ with low plants. The result also shows that LCZ with the compact mid rise building were on average $2.5 \%$ dryer at daytime and $1.25 \%$ dryer at night time than LCZ with low plants.
\end{abstract}

Key Words: urban heat island, urban dry island, local climate zones (LCZs),Landsat

\section{INTRODUCTION}

The faster-growing populations towards the cities and the climate change are one of the biggest problems. The cities are increasing and are highly concretized and compacted with tall buildings to accommodate the growing population. The population and built up has become one of the indexes of the development of cities. Such built structures and the cities are related to the increase of urban temperatures, energy consumption rate, waste production, raw material use, pollution agricultural to urban land conversion, biodiversity loss and shortage of water ${ }^{11}$.

The warming and drying of city area atmosphere compared to its countryside is called urban heat island (UHI) and urban dry island (UDI), respectively. There are hundreds of literature available, related to UHI in different cities of the world today. The results of UHI shows that after sunset the temperature in an urban environment $\left(\mathrm{T}_{\mathrm{U}}\right)$ cools almost linearly whereas the rural environment temperature $\left(T_{R}\right)$ cools exponentially ${ }^{2}$. UDI is the phenomenon where urban absolute humidity is lower than rural absolute humidity ${ }^{3}$. The typical way of investigation of UHI/UDI is by selecting the sites, the urban (highly dense) area and the rural area where there is almost no human influence in the environment. Either conventional fixed stations are established or the mobile temperature measuring instruments are run in both urban and rural areas to calculate the temperature difference $\left(\mathrm{T}_{\mathrm{U}-\mathrm{R}}\right)$ between them. The terms urban and rural are too ambiguous to define. They do not have definitive criteria to explain their boundaries. Some studies consider certain sized of cities as the urban area and the other studies consider other sized as the urban area. The general image of the rural area is an area not having man-made structure and mainly covered with plants and vegetation. However, the type of vegetation is not defined within rural areas studies. Despite the number of previous UHI/UDI studies ${ }^{3445) 66}$, the study has lacked a proper standard 
Table 1 LCZ divided into built types and land cover types (Stewart and Oke, $(2012)^{6}$

\begin{tabular}{ll|ll}
\hline LCZ & Building Type & LCZ & Land cover types \\
\hline 1 & Compact high-rise & A & Dense trees \\
2 & Compact midrise & B & Scattered trees \\
3 & Compact low-rise & C & Bush,Scrub \\
4 & Open high-rise & D & Low plants \\
5 & Open midrise & E & Bare rock / paved \\
6 & Open low-rise & F & Bare soil/sand \\
7 & Lightweight low-rise & G & Water \\
8 & Large low-rise & & \\
9 & Sparsely built & & \\
10 & Heavy industry & & \\
\hline
\end{tabular}

to categorise urban and rural areas. Hence, this has created the variation in the results and it is difficult to compare the individual urban / rural related studies from one city to another.

In order to deal with such kind of problem Stewart and $\mathrm{Oke}^{7)}$ have introduced a contextual and relevant solution by dividing various microclimatic environment into a particular zone known as Local Climate Zone (LCZ) having a minimum radius of 200-500 metres. The LCZ is mainly divided into built types and land cover types. Built types are further divided into ten zones based on structure, fabric, coverage and metabolism. Likewise, land cover types are further divided into seven zones as shown in Table 1. The combination of different zones can be used as a classification, depending on the actual field situation. To have uniformity in local climate zonation, boundary values for each parameter are fixed to classify each zones.

The main objective of this study is to determine the UHI and UDI effect on Matsuyama plane during 2015 summer based on LCZ and compare the UHI values with the similar studies available in different cities. The UDI effect based on LCZ is the first one because humidity has not been taken into consideration in terms of LCZ impact. In this study, we have divided Matsuyama plane into different LCZ types and studied the relationship between LCZ and UHI/UDI.

\section{MATERIALS AND METHODS}

\section{(1) Site description}

Matsuyama is located in the northwestern part of Shikoku Island, Japan. The Matsuyama plain is mainly an alluvial fan, which was formed by the material deposited through the flooding of the Shigenobugawa River and its territorials. The plain area runs about $20 \mathrm{~km}$ from east to west and is about 17 $\mathrm{km}$ from north to south with a total area of about 100 $\mathrm{km}^{2}$. The population of the plain is approximately

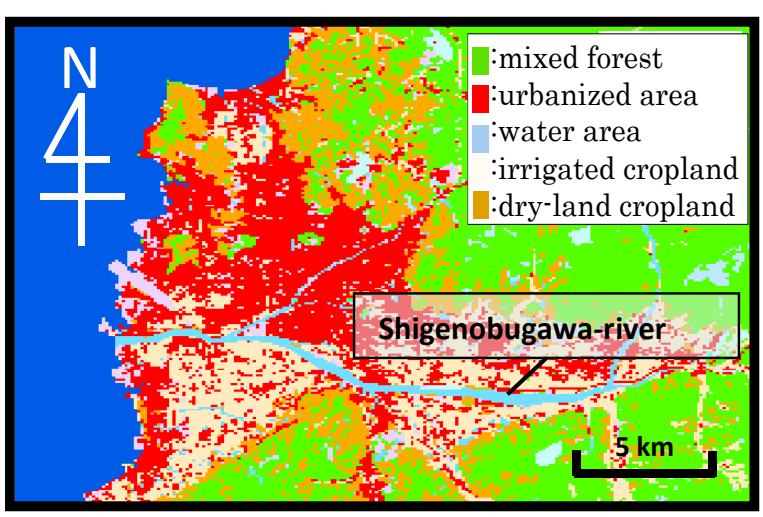

Fig.1 Land use category of National Land Numerical Information and location of observations

0.51 million, most of which is concentrated in the northern part. The plain has become more urbanized since the 1980s. The northern part of the river is densely populated, whereas the southern part consists almost entirely of rice paddy fields and sparsely built area. The plane is surrounded by the mountain to the east and south. To the north and west is the inland sea coastal area as shown in Fig.1.

\section{(2) LCZ mapping of the study area}

Several LCZ mapping schemes are available so far. For example Lelovics et al. ${ }^{8)}$ follows a manual sampling of individual grid cells using Geo-Wiki, digitization of homogeneous LCZs and a GIS-based approach using building data. Gamba et al. ${ }^{9)}$ and Weng ${ }^{10)}$ follow object-based image analysis. Bechtel et al. ${ }^{11)}$ and Bechtel and Daneke ${ }^{12)}$ follow supervised pixel-based classification. In this study, we have followed the methodology which is provided by World Urban Database and Access Portal Tools (WUDAPT $)^{13)}$. WUDAPT has introduced a simple workflow, which makes the procedure universal, low level of data requirements, comparable to different cities and operators, computationally and financially inexpensive and easy. Important aspects, preparation, and tools of the implement workflow are shown in Fig.2. In this mapping process, Google Earth is free, easy to use and high-resolution imagery for most cities is used for identifying the appropriate training sites (Fig.3a)). The Landsat data which is used in this study for the classification can easily be acquired from the U.S. Geological Survey Earth explorer interface (Fig.2a)). For the geometrical preprocessing and the classification of the map, System for Automated Geoscientific Analysis (SAGA) was used as a platform. First Landsat images were downloaded and then coropped to the region of interest (ROI). Digitised training areas using Google Earth were also also loaded to SAGA in KML format. The layers were then merged and coordinate were transformed. 
a)

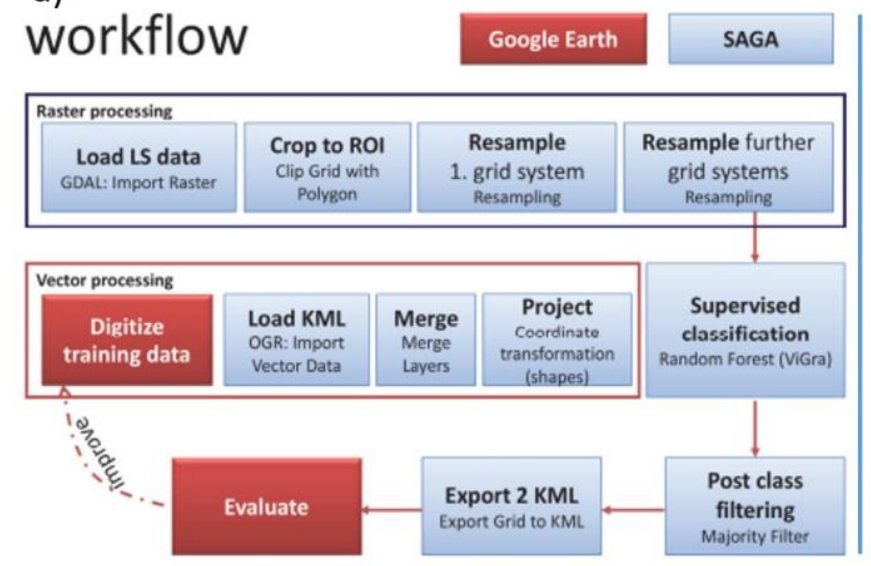

b)

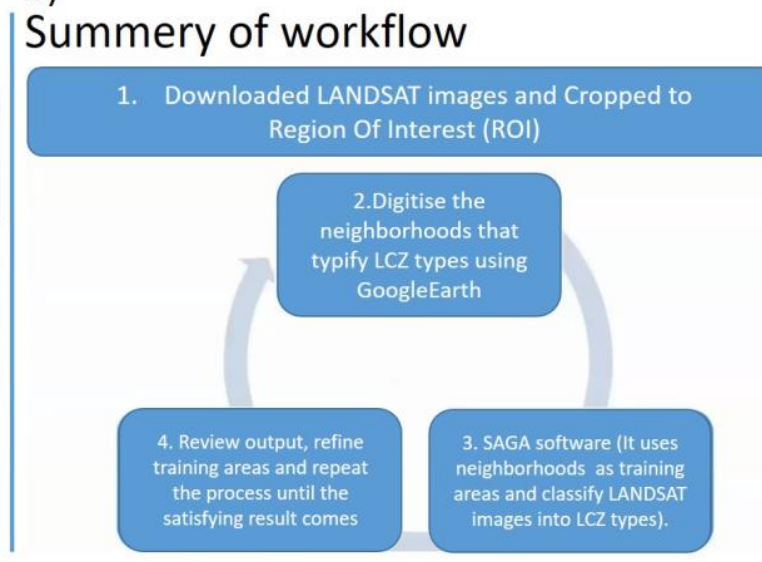

Fig.2 Overview of the mapping procedure. a) workflow ${ }^{11)}$; b) Summery of workflow

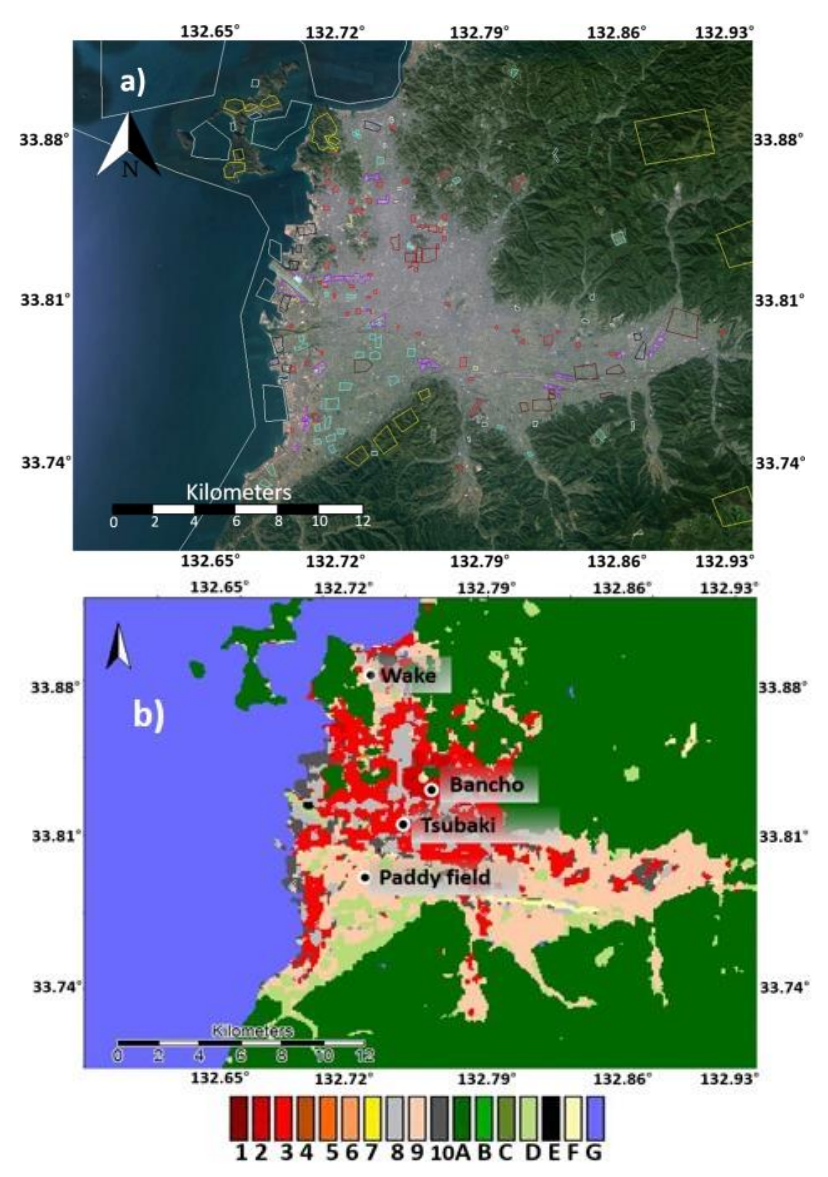

Fig.3 a) digitization of training areas in Google Earth b) LCZ map derived from Landsat Image

Resampling followed by resampling was conducted and post classification was applied to get the LCZ map. The processed LCZ map was further tested in Google Earth platform for the verification. Corrections were made by adding the training areas if necessary and the same process was continued to create the representative LCZ map (Fig.3b)).

\section{(3) Experimental setup}

The analysis of UHI and UDI of Matsuyama under favourable condition was considered in the context of LCZ. The approach was based on a measurement made at the fixed station. Four out of twenty-five meteorological stations available in Matsuyama plane for different atmospheric studies were selected to represent the unique LCZ area. Other twenty stations either represents the same LCZ or are located in high wind places like coastal area or the gorge. U23-001, onset, (thermos- mono hydrometers) was installed into a Stevenson screen at three elementary schools and in a natural ventilation shelter at open paddy field (Table 2).

As mentioned earlier, Matsuyama is covered by sea from the western side and the eastern side is covered with mountains. Places near to the sea and the mountain gorge experiences high wind, which is not favorable for the investigation of UHI/UDI. Such windy places are avoided while selecting the stations. The sensors are calibrated in the laboratory every year so that the relative standard error for temperature and relative humidity is less than $0.1{ }^{\circ} \mathrm{C}$ and $0.6 \%$ respectively. To obtain UHI/UDI favorable condition the average wind speed, cloud coverage (sunshine time) and average precipitation were checked by using the Japanese Meteorological Agency's official website ${ }^{14)}$ (Table 3).

To avoid the cloudy and windy condition, we have selected August 1 to 6 as favorable days as shown in Table 3. The period from 21:00 to 6:00 and 7:00 to 19:00 were selected for the nighttime and daytime, respectively. The spatial deviation of temperature and humidity was calculated as follows.

$$
\begin{aligned}
& \bar{T}_{i}{ }_{i}=\bar{T}_{i}-\tilde{\bar{T}} \\
& \overline{A H}_{i}{ }_{i}=\overline{A H}_{i}-\tilde{A H}
\end{aligned}
$$

Where $\bar{T}_{i}$ and $\overline{A H}_{i}$ are the temporal mean temperature and humidity at station $i$, and $\tilde{\bar{T}}$ and $\widetilde{A H}$ are 
the spatial mean of $\bar{T}_{1}$ to $\bar{T}_{4}$ and $\overline{A H}_{1}$ to $\overline{A H}_{4}$, respectively.

\section{RESULTS AND DISCUSSION}

\section{(1) Comparison of temperature}

Paddy field and Bancho being the low plant area (LCZ D) and compact midrise (LCZ 2) has the higher temperature in the daytime of all analysis days (see Fig.4). At night, compact midrise (Bancho) has the highest temperature whereas low plant area (paddy field) has the lowest one. On an average a difference of about $2^{\circ} \mathrm{C}$ between the compact midrise and low plant LCZ was recorded across the 6 nights, though the largest difference recorded was on 3 August $\left(2.5^{\circ} \mathrm{C}\right)$. Fig.4 b) shows that the stations located within high building coverage (LCZ 2 and 3) consistently exhibit positive thermal anomalies each night throughout the observation days compared to stations with higher pervious coverage (LCZ D and 6). Open low-rise (Wake, LCZ 6) which is a mix of both rural and urban area is almost neutral.

(2) Comparison of the study to other similar
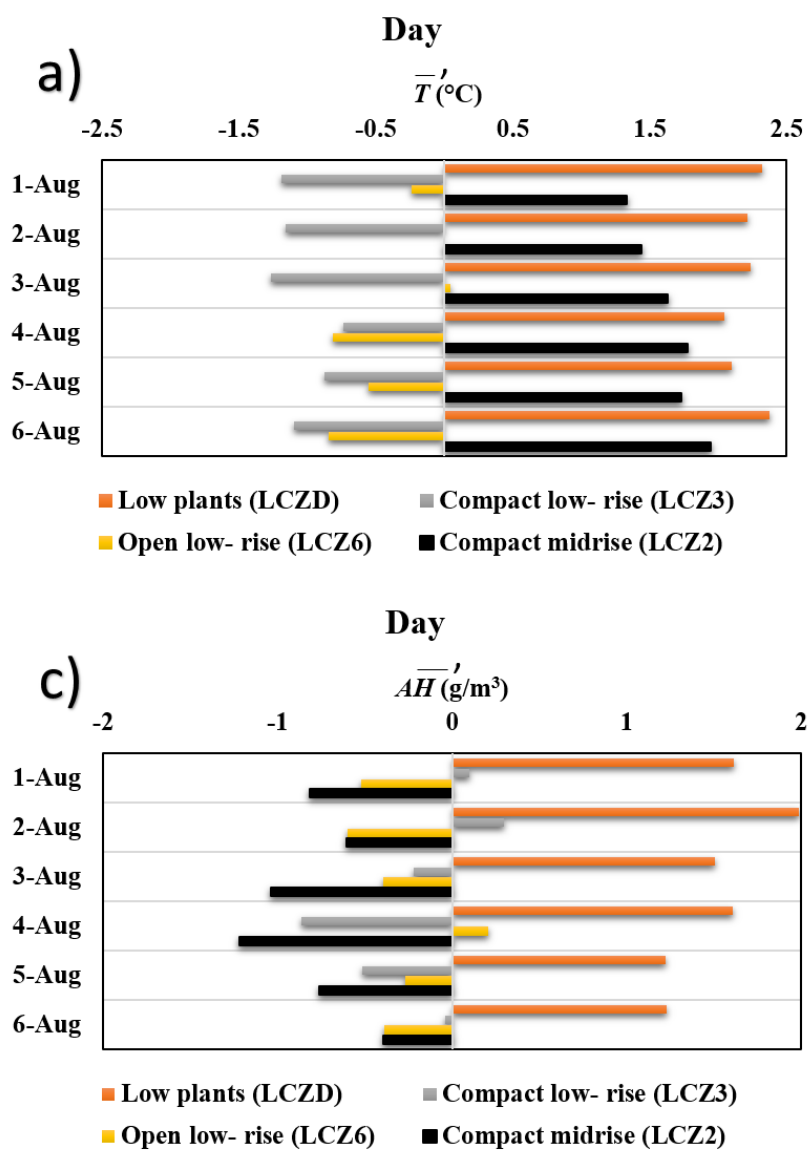

\section{studies}

As the concept of LCZ is new and was started only from $2012^{7)}$, there are not much LCZ based UHI studies. Some of the similar studies are available for comparison (Table 4) ${ }^{15) 16) 17718)}$. The relationship

Table 2 Observation of temperature and Relative humidity stations

\begin{tabular}{lllll}
\hline $\begin{array}{l}\text { Observation } \\
\text { Point }\end{array}$ & $\begin{array}{l}\text { LCZ } \\
\text { Type }\end{array}$ & $\begin{array}{l}\text { Longitude } \\
\left({ }^{\circ}\right)\end{array}$ & $\begin{array}{l}\text { Latitude } \\
\left.\mathbf{(}^{\circ}\right)\end{array}$ & $\begin{array}{l}\text { Altitude } \\
(\mathbf{m}, \mathbf{T P})\end{array}$ \\
\hline Paddy field & $\mathrm{D}$ & 132.74 & 33.80 & 7 \\
Tsubaki & 3 & 132.76 & 33.81 & 15 \\
Wake & 6 & 132.73 & 33.89 & 2 \\
Bancho & 2 & 132.77 & 33.84 & 24 \\
\hline
\end{tabular}

Table 3 Mean wind speed, Sunshine time and precipitation dataset obtained from Matsuyama meteorological observatory for the favorable days

\begin{tabular}{cccc}
\hline Days & $\begin{array}{c}\text { Wind speed } \\
(\mathbf{m} / \mathbf{s})\end{array}$ & $\begin{array}{c}\text { Sunshine } \\
\text { time }\end{array}$ & $\begin{array}{c}\text { Precipitation } \\
(\mathbf{m m})\end{array}$ \\
\hline 1-August & 2.0 & 12.9 & 0.0 \\
2-August & 1.9 & 12.4 & 0.0 \\
3-August & 2.1 & 12.6 & 0.0 \\
4-August & 2.2 & 11.4 & 0.0 \\
5-August & 2.1 & 11.8 & 0.0 \\
6-August & 2.0 & 09.2 & 0.0 \\
\hline
\end{tabular}
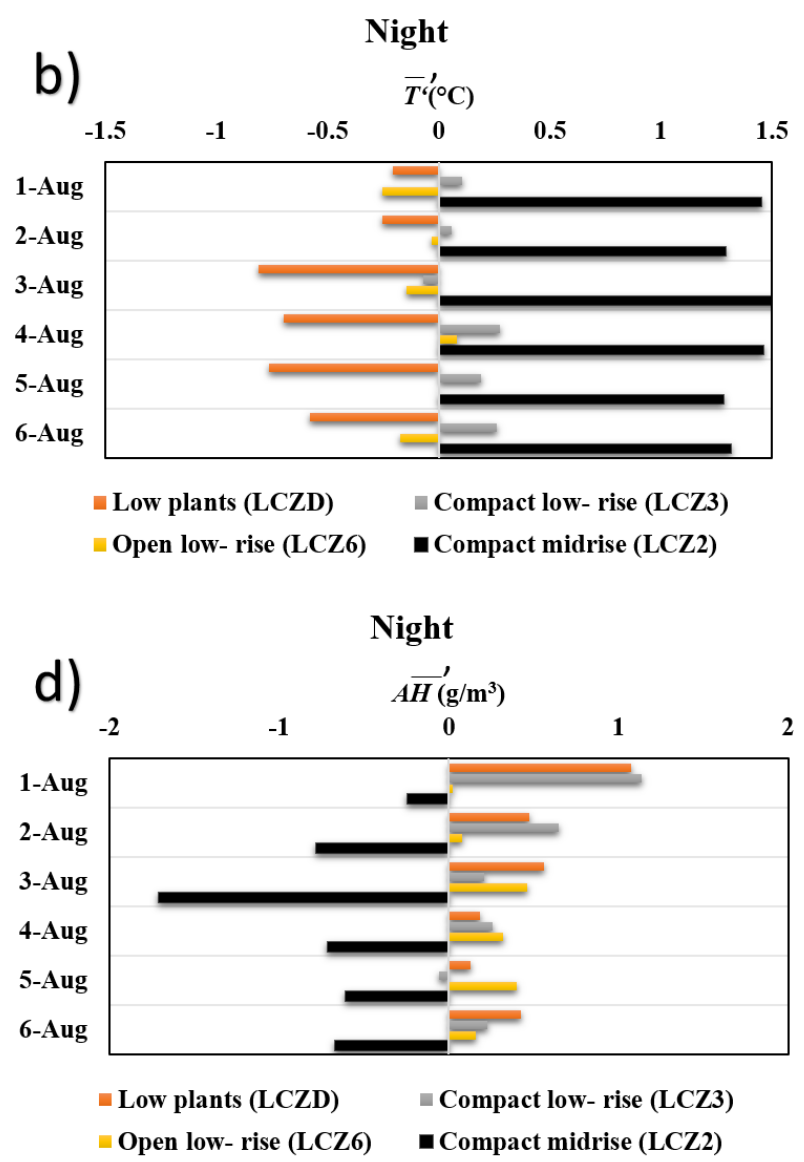

Fig.4 Diurnal (7:00-19:00, JST) and Nocturnal (21:00-6:00, JST) thermal $\left(T_{F(i)}^{\prime}\right)$ and absolute humidity $\left(A H_{F(i)}^{\prime}\right)$ anomalies for the four fixed stations for 1 August to 6/7 August. Each stations (1-4) is represented by the bars below and identified by the lcz in which they are placed 
Table 4 Comparison of this study to other similar studies (i.e $\mathbf{T}_{\mathbf{L C Z x}}-\mathbf{T}_{\mathbf{L C Z y}}$ ). The fixed values from Matsuyama area averaged from the 6 nights of Observation during UHI favorable condition. "---“"represents" value not available".

\begin{tabular}{|c|c|c|c|c|c|c|c|}
\hline \multirow[b]{2}{*}{$\begin{array}{l}\text { Intra-Urban } \\
\text { comparision }\end{array}$} & \multicolumn{2}{|l|}{ This study } & \multicolumn{4}{|c|}{ Similar studies from other sites } & \multirow[b]{2}{*}{ Uppsala $^{6}$} \\
\hline & Matsuyama & Dublin $^{1}$ & Nancy $^{2}$ & Nagano $^{3}$ & Berlin $^{4}$ & Vancouver $^{5}$ & \\
\hline $\mathrm{LCZ}_{2}-\mathrm{LCZ}_{3}$ & 1.3 & 0.5 & $\begin{array}{c}-- \\
--\end{array}$ & 1.7 & $\begin{array}{c}-- \\
--\end{array}$ & --- & --- \\
\hline $\mathrm{LCZ}_{2}-\mathrm{LCZ}_{6}$ & 1.5 & 2.2 & 1.8 & 2 & --- & $* 2.3$ & $* * 1.5$ \\
\hline \multicolumn{8}{|c|}{$\begin{array}{l}\text { Urban and Rural } \\
\text { comparison }\end{array}$} \\
\hline $\mathrm{LCZ}_{2}-\mathrm{LCZ}_{\mathrm{D}}$ & 2 & 4.2 & 4.4 & 3.2 & --- & $* 6.3$ & 3.3 \\
\hline $\mathrm{LCZ}_{3}-\mathrm{LCZ}_{\mathrm{D}}$ & 0.7 & 3.9 & --- & 1.5 & $* * 1.5$ & --- & --- \\
\hline $\mathrm{LCZ}_{6}-\mathrm{LCZ}_{\mathrm{D}}$ & 0.5 & 2 & 2.4 & 1.2 & 0.8 & 4 & $* * 1.8$ \\
\hline
\end{tabular}

${ }^{1}$ Fixed station average value obtained from three UHI fabourable nights(15), ${ }^{2}$ Reported decadal average, Table 2 in (16); ${ }^{3}$ Average differences during nighttime period approximately $3 \mathrm{~h}$ after sunset, Table 1 in (17); ${ }^{4}$ Reported Annual departures used, Fig. 3 in (18); ${ }^{5}$ Nocturnal traverses during November 1999, Fig.5 in (18); ${ }^{6}$ Reported Annual departures used, Fig.8 in (18); * Value for LCZ1 used in place of LCZ 2; ** Value for LCZ5 used in place of LCZ 6 (in place of LCZ 3 for Berlin)

between different LCZ air temperatures obtained here corresponds well with recent works done in different cities elsewhere. Table 4 shows the comparison of air temperature between intra-urban and urban-rural areas. The values, which are not available for the comparison, are replaced by the closest LCZ air temperature value available for the comparison (the values marked with $*$ or $* *$ ).

\section{a) Intra-urban comparison}

The comparison of the temperature difference between the LCZs based on building types was compared with other similar studies. In this comparison $\mathrm{LCZ}_{2}-\mathrm{LCZ}_{6}$ with a value of $1.5^{\circ} \mathrm{C}$ is greater than $\mathrm{LCZ}_{2}-\mathrm{LCZ}_{3}$ with a value of $1.3^{\circ} \mathrm{C}$ in Matsuyama. This is because $\mathrm{LCZ}_{3}$ is densely concretized and has higher temperature compared to $\mathrm{LCZ}_{6}$. The tendency of slight increase of temperature discussed above is similar to Nagano's result as shown in Table 4. Interestingly, $\mathrm{LCZ}_{2}-\mathrm{LCZ}_{3}$ of Matsuyama and Nagano is not similar with Dublin. This may be due to the difference in urban fabric. Low-rise $\left(\mathrm{LCZ}_{3}\right)$ buildings in Japan are generally built with wood, while the construction material used for the same category in Dublin is concrete. Therefore the temperature of wooden structure tends to decrease more rapidly and as a result $\mathrm{LCZ}_{2}-\mathrm{LCZ}_{3}$ in Japanese cities tend to be larger than that of Dublin at night. The differences may also be due to other possible factors like study period, latitude length of the day, season, instrumentation, setting, and background climate.

\section{b) Urban and rural comparison}

The comparison of the temperature difference between the LCZs based on different building types and low plants $\left(\mathrm{LCZ}_{\mathrm{D}}\right)$ was compared with other similar studies. The value of $\mathrm{LCZ}_{2}-\mathrm{LCZ}_{\mathrm{D}}$ tends to be larger than that of the intra-urban comparison as shown in Table 4. The difference of $\mathrm{LCZ}_{2}-\mathrm{LCZ}_{\mathrm{D}}$, $\mathrm{LCZ}_{3}-\mathrm{LCZ}_{\mathrm{D}}$, and $\mathrm{LCZ}_{6}-\mathrm{LCZ}_{\mathrm{D}}$, respectively, is decreasing in order in Matsuyama. The trend is similar with the other study areas. However, the values are different among cities. It may be because the, study period, setting, and background climate is different. The exact nature of LCZ classes in each study may also differ in terms of land use and building materials (Alexander et al., 2015 ${ }^{16)}$ ).

\section{(3) Comparison of humidity}

Comparison of absolute humidity $\left(\mathrm{A}_{\mathrm{HF}}\right)$ between different LCZ categories ( Fig.4c) and 4d) shows that low plant (LCZ D) has the highest and compact midrise (Bancho, LCZ 2) has the lowest value of all both in the daytime and nighttime. The ranking of LCZ (in terms of + or - absolute humidity) more or less appears to follow a logical pattern where built up areas exhibit negative $A_{H F}$ values and the areas with vegetation exhibit positive $\mathrm{A}_{\mathrm{HF}}$ values. On an average, a difference of about $2.5 \%$ between the urban LCZ and rural LCZ was recorded in the daytime across the 6 days, and that in the nighttime was $1.25 \%$. It shows the urban dry island phenomena is significant at daytime during fine days compared to nights.

\section{CONCLUSIONS}

The concept of Local Climate Zone (LCZ) classification is an outstanding concept for the urban/ rural studies on the global scale. This study shows the importance of LCZ categorization as an initial step that helps in the comparison, design, implementation and interpretation of urban meteoro- 
logical studies. In this study, a maximum nocturnal air temperature of about $2.5^{\circ} \mathrm{C}$ was detected between urban and non-urban LCZ ( $\left.\mathrm{T}_{\mathrm{LCZ} 2}-\mathrm{T}_{\mathrm{LCZ}} \mathrm{D}\right)$. LCZ with compact mid rise building were on an average $2.5 \%$ dryer at daytime and $1.25 \%$ dryer at nighttime than LCZ with low plants. It also suggests that urban dry island phenomena are significant at daytime during fine days compared to nights. The results show that the magnitude of UHI and UDI highly depends on the LCZ type and they can be used to make a sensible interpretation of the temperature and absolute humidity values in urban neighborhoods where there are no observations.

ACKNOWLEDGMENT: We thank WUDAPT team for helping us in the process of creating the LCZ map. We also acknowledge the schools for kindly allowing us to locate stations on their premises. This work was supported by JSPS KAKENHI Grant Number 15K06236.

\section{REFERENCES}

1) Santamouris, M.: Energy and Climate in the Urban Built Environment, James \& James, London, UK, 2001.

2) Munn, R. E., Mac Cracken, M. C., and Perry, J. S.: Encyclopedia of Global Environment change, Wiley, ISBN 978-0-471-97796-4., 2012.

3) Moriwaki, R., Watanabe, K. and Morimoto, K.: Urban Dry Island Phenomenon and its impact on cloud base level, Journal of JSCE, Vol. 1, pp. 521-529, 2013.

4) Sakakibara, Y., Hara, Y. and Kato, Y.: The feature of heat island intensity with two extra stations method in the southeast part of Koshigaya city, Tenki, Vol.43, No. 8,pp.537-543, 1996. ( in Japanese).

5) Mikami, T.: Urban heat island phenomenon and their causing factors: A case study of Tokyo Metropolish, J. Geography (Chigaku Zasshi), Vol.114, No.3, pp.496-506, 2005. (in Japanese)

6) Fujimori, Y., Hayashi, Y. and MOriwaki, R.: Characteristic of urban heat island phenomenon in Matsuyama plane, Annual Journal of Hydraulic Engineering, JSCE, Vol. 54, PP. 313-318, 2001. (in Japanese).

7) Steward, I.D., and Oke, T. R.: Local Climate Zones for Urban Temperature Studies. Bull. Am. Meteorol. Soc., 93, 1879-1900, doi:10.1175/BAMS-D-11-00019.1. 2012.

8) Lelovics, E., Unger, J., Gál, T., and Gál, C. V.: Design of an urban monitoring network based on Local Climate Zone mapping and temperature pattern modelling. Clim. Res., 60, pp. 51-62, doi: 10.3354/cr01220, 2014.

9) Gamba, P., Lisini, G., Liu, P.,Du P. and Lin,H.: Urban climate zone detection and discrimination using object-based analysis of VHR scenes. Proc. 4th GEOBIA,pp. 7-9,2012.

10) Weng, Q.: Global Urban Monitoring and Assessment through Earth Observation. CRC Press,pp. 420,2014.

11) Bachtel, B., Alexander, P.J., Böhner, J., Ching, J., Conrad, O., Feddema, J., Mills, G., See, L., and Stewart, I: Mapping Local Climate Zones for a Worldwide Database of the Form and Function of Cities, ISPRS Int. J. Geo-Inf, doi:10.3390/ijgi4010199, pp. 199-219,2015.

12) Bechtel, B., and Daneke, C.: Classification of Local Climate Zones Based on Multiple Earth Observation Data. IEEE J. Sel. Top. Appl. Earth Obs. Remote Sens.,Vol 5, pp.1191-1202.,2012.

13) World Urban Database and Access Portal Tools: http://www.wudapt.org/, accessed on 11 $1^{\text {th }}$ Aug.2016.

14) Japan Meteorological Agency: http://www.jma.go.jp, accessed on $8^{\text {th }}$ Aug. 2016.

15) Alexander P.J. and Mills G.:Local Climate and Dublin's Urban Heat Island,Atmosphere, Vol 5,pp. 755-774, doi:10.3390/atmos5040755,2014.

16) Fenner, D., Meier, F., Scherer, D., Polze, and A.: Spatial and temporal air temperature variability in Berlin, Germany, during the years 2001-2010. Urban Clim., doi:10.1016/j.uclim.2014.02.004, 2014.

17) Leconte, F.; Bouyer, J.; Claverie, R.; Pétrissans, M. Using local climate zone scheme for UHI assessment: Evaluation of the method using mobile measurements. Build. Environ., doi:10.1016/ j.buildenv.2014.05.005,2014

18) Stewart, I.D., Oke, T.R.; Krayenhoff, E.S. Evaluation of the "local climate zone" scheme using temperature observations and model simulations. Int. J. Climatol., Vol 34, 1062-1080, 2014.

(Received September 30, 2016) 